\title{
On the thermal sensitivity of unbound granular pavement layers
}

\section{Levenberg, Eyal; Rocchi, Irene}

Published in:

International Journal of Pavement Research and Technology

Link to article, DOI:

10.1007/s42947-019-0082-4

Publication date:

2020

Document Version

Peer reviewed version

Link back to DTU Orbit

Citation (APA):

Levenberg, E., \& Rocchi, I. (2020). On the thermal sensitivity of unbound granular pavement layers. International Journal of Pavement Research and Technology, 13, 32-39. https://doi.org/10.1007/s42947-019-0082-4

\section{General rights}

Copyright and moral rights for the publications made accessible in the public portal are retained by the authors and/or other copyright owners and it is a condition of accessing publications that users recognise and abide by the legal requirements associated with these rights.

- Users may download and print one copy of any publication from the public portal for the purpose of private study or research.

- You may not further distribute the material or use it for any profit-making activity or commercial gain

- You may freely distribute the URL identifying the publication in the public portal

If you believe that this document breaches copyright please contact us providing details, and we will remove access to the work immediately and investigate your claim 


\title{
On the thermal sensitivity of unbound granular pavement layers Eyal Levenberg and Irene Rocchi
}

\begin{abstract}
The reversible mechanical behavior of unbound granular layers (UGLs) is commonly characterized by a stress-state dependent resilient modulus. This paper investigated the dependency of in situ resilient modulus upon a change in temperature above freezing conditions, i.e., the thermal sensitivity of UGLs in pavement systems excluding frost action. Such sensitivity is usually ignored in design and analysis because, on a material level, resilient modulus parameters are temperature independent. A model was developed to analyze this dependency by considering the stress-state changes that arise when UGLs are suppressed from thermally expanding or contracting. The formulation was incremental, based on linear thermoelasticity equations, and required as input readily available information; it assumed that changing temperature conditions are exogenous to the model and that no external loads are applied. A transcendental equation was subsequently derived, from which the sought sensitivity of UGLs could be resolved and quantified. Based on a parametric investigation of the model, covering a wide range of representative parameters, it is concluded that UGLs exhibit non-negligible thermal sensitivity. The extent of the calculated sensitivity coincides with field observations based on deflection testing, and also with seasonal factors that are traditionally applied to adjust field-measured moduli. Ultimately, the study shows that resilient modulus of UGLs is governed by an initial stress-state that is associated with a certain reference temperature level, and also by the temperature change compared to the reference.
\end{abstract}

Keywords: Unbound granular material, Resilient modulus, Thermal sensitivity, Thermoelasticity, Thermal expansion.

\section{Introduction}

The concept of resilient modulus, introduced several decades ago [1-6], is nowadays widely applied to describe the reversible constitutive behavior of well-compacted unbound granular materials (UGMs) [7-10]. In analogy with Young's modulus, resilient modulus (commonly denoted by $M_{R}$ ), represents a stress-state dependent elastic modulus. For UGMs in unfrozen conditions $M_{R}$ is typically expressed in terms of the first stress invariant $I_{1}$ (positive in compression) and the second invariant of the stress deviator tensor $J_{2}[11,12]$ :

$$
M_{R}=M_{R}\left(I_{1}, J_{2}\right)
$$

where $I_{1}=\sigma_{1}+\sigma_{2}+\sigma_{3}, 6 J_{2}=\left(\sigma_{1}-\sigma_{2}\right)^{2}+\left(\sigma_{2}-\sigma_{3}\right)^{2}+\left(\sigma_{1}-\sigma_{3}\right)^{2}$, and the three $\sigma_{i}$ 's are effective principal stresses, i.e., containing moisture suction effects [13].

The resilient Poisson's ratio $v_{R}$ is also stress-state dependent $[4,14,15]$, formulated in a manner that is linked with $M_{R}$ to guarantee stress-path independency and energy conservation [13,16-18]. Nonetheless, $v_{R}$ is frequently treated as constant, possibly because it varies within a narrow range and possibly due to experimental difficulties in obtaining reliable values.

Excluding frost action, resilient properties of UGMs have always been regarded as temperature independent due to the thermally inert nature of the individual aggregates, i.e., the mineral elastic coefficients are insensitive to temperature changes within the ranges encountered in typical engineering applications. A recent study reaffirmed this interpretation by performing resilient modulus experiments 
at several temperature levels [19]. Accordingly, unbound granular layers (UGLs) are commonly treated as thermally insensitive for pavement design and analysis purposes [9,20-24].

However, UGLs must exhibit thermal sensitivity when temperature changes take place. The sensitivity is associated with changes in stress-state that originate from the material's tendency to thermally expand or contract - and the kinematic suppression to do so. This thermomechanical effect is the reason for measured variations in lateral earth pressure on structures upon variations in temperature [25-28]. This mechanism has also been reproduced in discrete element simulations of confined granular media $[29,30]$. For UGLs, such thermal sensitivity mechanism was noted and addressed by Chandra et al. [31,32]. The impetus for the work was the observation, based on deflection testing, that UGLs in low-volume roads exhibited $M_{R}$ fluctuations in correlation to temperature (excluding frost action). The fluctuations were non-negligible in magnitude, e.g., an increase in UGL temperature from $10{ }^{\circ} \mathrm{C}$ to $40{ }^{\circ} \mathrm{C}$ was accompanied by an increase in backcalculated $M_{R}$ of about $50 \%$.

A micromechanical theory was proposed by Chandra et al. for modeling the observed thermal sensitivity. The material was viewed as a three-dimensional collection of equiradii linear elastic spheres in contact. It was further assumed that the spheres resided inside a closed rigid container preventing any bulk expansion from taking place. Subsequently, a formula was derived for quantifying the change in $I_{1}$ resulting from a temperature increment - from which a corresponding change in $M_{R}$ could be calculated (after assuming the initial stress-state and $M_{R}$ as a power-law of $I_{1}$ ). This formula considered the packing level of the spheres (i.e., porosity), the individual sphere properties - elasticity coefficients and coefficient of volumetric thermal expansion, yet it was missing a relevant input: the resilient properties prevailing prior to the temperature increment. While good reproducibility of backcalculated $M_{R}$ values was noted in the study, the work has not been widely accepted in the pavement engineering community. One possible reason is the utilization of a micromechanical approach, which is perceived (predominantly) as a research tool suited for gaining insight into particle-scale interactions, and not as a geotechnical design and analysis tool [33]. Another possible reason is the unrealistic assumption of the spheres being fully confined in a rigid box, given that for pavement systems, UGLs are unrestricted to thermally expand in the vertical direction (at least).

Subsequently, it is the objective of the current contribution to develop a method for quantifying the thermal sensitivity of UGLs in pavement systems, i.e., the dependency of $M_{R}$ on temperature changes. Three main attributes are sought as means of enhancing the possible acceptance and utility of the work: (i) developing a formulation within a continuum mechanics framework, (ii) considering representative in situ boundary and initial conditions, and (iii) establishing all required input parameters on readily available information or on data obtainable from standard test procedures.

The paper commences by introducing the governing thermoelastic equations for an UGM element; these are then morphed to address the situation of an UGL - for which thermal sensitivity is quantified. Then, calculation steps are demonstrated and results are generated as part of a parametric investigation. The paper terminates with a discussion about the model assumptions and limitations, followed by a short summary of the findings and some concluding remarks.

\section{Thermoelastic analysis}

Consider an isotropic and well-compacted UGM element under a certain temperature level $T$ and a stress-state defined in terms of the three principal effective stresses. In this reference state the prevailing resilient properties are $M_{R}$ and $v_{R}$. Upon a small temperature increment $d T$ or upon a small stress- 
state increment $d \sigma_{i}$ (or both), a corresponding increment of principal strains $d \varepsilon_{i}$ will be induced. Assuming all increments are infinitesimally small, the usual linear thermoelasticity formulation applies:

$$
\left[\begin{array}{l}
d \varepsilon_{1} \\
d \varepsilon_{2} \\
d \varepsilon_{3}
\end{array}\right]=\frac{1}{M_{R}}\left[\begin{array}{ccc}
1 & -v_{r} & -v_{R} \\
-v_{R} & 1 & -v_{R} \\
-v_{R} & -v_{R} & 1
\end{array}\right]\left[\begin{array}{l}
d \sigma_{1} \\
d \sigma_{2} \\
d \sigma_{3}
\end{array}\right]-\alpha\left[\begin{array}{l}
d T \\
d T \\
d T
\end{array}\right]
$$

where $\alpha$ denotes the coefficient of linear thermal expansion of the UGM. Some guidance for selecting representative $\alpha$ values can be obtained from examining the few existing studies dealing with volume changes in sands under thermal cycles [34-36]. Excluding cases addressing loose to intermediate relative densities, it was observed that dense sand exhibits volume increase that is almost identical to the thermal expansion exhibited by individual sand particles. Accordingly, for UGMs in pavement applications the value of $\alpha$ can be chosen based on the aggregate rock type. It was also pointed out in these studies that the observed expansion was stress independent - confirming that $\alpha$ in Eq. (2) may be taken as constant.

To quantify the thermal sensitivity of an UGL, the pavement system is modeled as a stratified half-space composed of isotropic materials. Referring to Fig. 1, a Cartesian coordinate system is positioned at the half-space surface with the $z$-axis pointing down into the medium, while both the $x$ and $y$ axes are oriented parallel to the layering. No external loads are applied, and temperature conditions are assumed to be above freezing, timewise constant, spatially uniform in the $x y$ plane, and with variability only along the depth, i.e., $T=T(z)$. In this configuration, the principal stress directions coincide with the chosen coordinate directions, i.e., $\sigma_{1}$ with the $z$-axis, $\sigma_{2}$ with the $x$-axis, and $\sigma_{3}$ with the $y$-axis. Also, due to symmetry, the two lateral effective stresses are identical, i.e., $\sigma_{2}=\sigma_{3}$.

For any UGM element that is unsaturated (or saturated, but resides above the water table level), the effective vertical stress is defined by the depth of the element below the surface $z_{0}$, the weighted average total unit-weight of all overlying layers $\gamma_{t}$, and the prevailing moisture suction $S$, i.e., $\sigma_{1}=z_{0} \gamma_{t}-S$ where $S$ itself is negative - representing pore water tension. The corresponding lateral effective stress is $\sigma_{2}=K_{0} \sigma_{1}$, where $K_{0}$ is the coefficient of at-rest earth pressure.
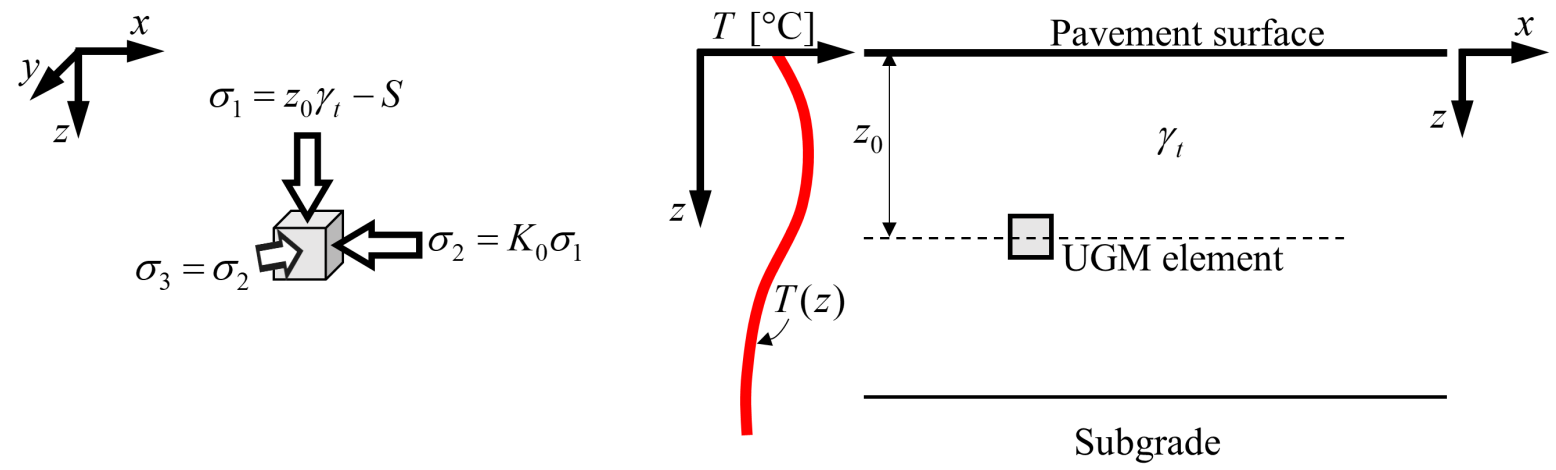

Fig. 1. Assumed pavement model for thermal sensitivity analysis.

When the temperature profile slightly changes, all UGM elements located at the same depth experience an identical thermal increment. Due to the infinite lateral dimensions of the UGL, all elements are restrained from deforming laterally; also, given that the system is not externally loaded, the vertical stress-state remains unchanged. This situation can be inserted into Eq. (2) by setting $d \sigma_{2}=d \sigma_{3}, d \varepsilon_{2}=d \varepsilon_{3}=0$, and $d \sigma_{1}=0$; the outcome is: 


$$
M_{R} \frac{\alpha d T}{1-v_{R}}=d \sigma_{2}
$$

For any UGM element, this expression interrelates stress-state increments, thermal increments, and prevailing resilient properties. It can be viewed as the incremental analog to Westergaard's analysis of stresses induced in concrete plates upon exposure to a uniform temperature change [37]. In case of a non-infinitesimal temperature change a nonlinear version of Eq. (3) can be written by simply replacing $d T$ with $\Delta T$ and replacing $d \sigma_{2}$ with $\Delta \sigma_{2}$. The resulting equation is nonlinear because both $M_{R}$ and $v_{R}$ depend on stress-state through the stress invariants and hence on $\Delta \sigma_{2}$.

\section{Demonstrative application}

The above-described formulation is demonstrated here for quantifying the thermal sensitivity of an UGL. The following resilient modulus expression was adopted for this purpose [11]:

$$
M_{R}=\left(k_{1} P_{a}\right)\left(\frac{I_{1}}{P_{a}}\right)^{k_{2}}\left(\frac{\sqrt{2 J_{2} / 3}}{P_{a}}+1\right)^{k_{3}}
$$

where $P_{a}=100 \mathrm{kPa}$ denotes atmospheric pressure, and the three $k_{i}$ 's are unitless material parameters: $k_{1}$ and $k_{2}$ are positive while $k_{3}$ is negative. This $M_{R}$ expression was inserted into Eq. (3) along with all model definitions and symbols, and after assuming a constant $v_{R}$. Specifically, the stresses used in the invariant expressions $I_{1}$ and $J_{2}$ were: $\sigma_{1}=z_{0} \gamma_{t}-S, \sigma_{2}=K_{0} \sigma_{1}+\Delta \sigma_{2}$, and $\sigma_{3}=\sigma_{2}$. With some rearrangement, the following was obtained:

$$
\underbrace{\left(\frac{\left(k_{1} P_{a}\right)\left(\frac{\left(z_{0} \gamma_{t}-S\right)\left(1+2 K_{0}\right)+2 \Delta \sigma_{2}}{P_{a}}\right)^{k_{2}}}{\left(\frac{\left|2\left(z_{0} \gamma_{t}-S\right)\left(1-K_{0}\right)-2 \Delta \sigma_{2}\right|}{3 \sqrt{2} P_{a}}+1\right)^{-k_{3}}}\right)}_{M_{R}} \frac{\alpha \Delta T}{1-v_{R}}=\Delta \sigma_{2}
$$

This is a transcendental equation from which the sought thermal sensitivity of UGLs can be resolved. With all model parameters known, and for a given temperature increment $\Delta T$, it requires a numerical solution for $\Delta \sigma_{2}$. Since the expression is of the form $f\left(\Delta \sigma_{2}\right)=\Delta \sigma_{2}$ one possible solution scheme is fixed-point iteration. This scheme works by assuming $\Delta \sigma_{2}$, evaluating the left-hand side, treating the outcome as a new (improved) assumption for $\Delta \sigma_{2}$, and repeating until convergence is attained, i.e., until the left-hand side and right-hand side of Eq. (5) are sufficiently close [38]. Once $\Delta \sigma_{2}$ is found it also becomes possible to evaluate the $M_{R}$ (bracketed term) associated with the imposed temperature change $\Delta T$.

The coefficient of at-rest earth pressure $K_{0}$ in Eq. (5) corresponds to the initial UGL conditions associated with $\Delta T=0$. For any $\Delta T$, either positive or negative (also zero), the coefficient of at-rest earth pressure is denoted by $K_{0}^{\Delta T}$ such that $K_{0}^{\Delta T}=K_{0}+\Delta \sigma_{2} / \sigma_{1}$; expressing the fact that lateral stresses increase while vertical stresses remain constant. There is no safeguard mechanism in Eq. (5) against $K_{0}^{\Delta T}$ exceeding the passive earth pressure coefficient or falling below the active earth pressure coefficient. These bounds must be separately checked and enforced in order to ensure that the calculation results are physically meaningful and admissible. 
Eq. (5) was evaluated considering several $\Delta T$ 's covering a range of $50{ }^{\circ} \mathrm{C}$, from $\Delta T=-25^{\circ} \mathrm{C}$ to $\Delta T=+25^{\circ} \mathrm{C}$. Both bounds of this rage are relevant for pavements under service, e.g., an UGL constructed at $30^{\circ} \mathrm{C}$ that experiences a temperature of $5{ }^{\circ} \mathrm{C}$ corresponds to $\Delta T=-25{ }^{\circ} \mathrm{C}$, and an UGL constructed at $15{ }^{\circ} \mathrm{C}$ that experiences a temperature of $40^{\circ} \mathrm{C}$ corresponds to $\Delta T=+25{ }^{\circ} \mathrm{C}$. Moreover, a set of representative parameter values was chosen to serve as a reference; this set is summarized in Table 1. Also investigated was the influence of varying the parameter values (one at a time) on the calculation results; the considered ranges are also listed in Table 1.

Table 1

Parameter values for method demonstration

\begin{tabular}{|c|c|c|c|c|c|}
\hline Symbol & Parameter & units & $\begin{array}{c}\text { Reference } \\
\text { value }\end{array}$ & Range & Comments \\
\hline$z_{0}$ & Depth of UGM element & $\mathrm{m}$ & 0.3 & $0.1 \leftrightarrow 0.5$ & \multirow{3}{*}{ See Fig. 1} \\
\hline$\gamma_{t}$ & $\begin{array}{l}\text { Average total unit weight } \\
\text { of overlying layers }\end{array}$ & $\mathrm{kN} / \mathrm{m}^{3}$ & 23 & - & \\
\hline$S$ & Moisture suction & $\mathrm{kPa}$ & -15 & $-25 \leftrightarrow-5$ & \\
\hline$k_{1}$ & $M_{R}$ coefficient & unitless & 900 & $700 \leftrightarrow 1100$ & \multirow{3}{*}{ See Eq. (4) } \\
\hline$k_{2}$ & $M_{R}$ coefficient & unitless & 0.7 & $0.5 \leftrightarrow 0.9$ & \\
\hline$k_{3}$ & $M_{R}$ coefficient & unitless & -0.2 & $-0.4 \leftrightarrow 0.0$ & \\
\hline$K_{0}$ & $\begin{array}{l}\text { Initial at-rest earth } \\
\text { pressure coefficient }\end{array}$ & unitless & 3.0 & $2.0 \leftrightarrow 4.0$ & Refer to [39] \\
\hline$v_{R}$ & Resilient Poisson's ratio & unitless & 0.30 & $0.20 \leftrightarrow 0.40$ & Assumed stress-independent \\
\hline$\alpha$ & $\begin{array}{l}\text { Coefficient of linear } \\
\text { thermal expansion }\end{array}$ & $1 /{ }^{\circ} \mathrm{C}$ & $10 \cdot 10^{-6}$ & $(6 \leftrightarrow 14) \cdot 10^{-6}$ & Dolomite/granite/sandstone \\
\hline
\end{tabular}

Thermal sensitivity calculation results are shown in Figs. 2 and 3; each figure contains four charts that depict resilient modulus versus thermal increment. Every chart contains several curves with the central curve (solid line) common to all; this central curve represents the thermal sensitivity for the reference parameter set listed in Table 1. The other curves (dashed lines) depict the outcome of varying one of the parameter values while keeping all others constant. The influence of varying the resilient modulus properties, i.e., the three $k_{i}$ 's and the Poisson's ratio $v_{R}$ is shown in Fig. 2. The influence of varying parameters related to the initial stress-state, $K_{0}, z_{0}$, and $S$, as well as varying the thermal expansion coefficient $\alpha$, is shown in Fig. 3.

Discussed first is the behavior of the reference curve. Initially, before any temperature increment is applied ( $\Delta T=0$ ), the $M_{R}$ value is $117 \mathrm{MPa}$. This value can be simply obtained by inserting the reference parameter set into Eq. (4); it is graphically denoted across all charts by a small hollow circular marker superposed over the solid lines. As $\Delta T$ increases or decreases from zero, the reference curve exhibits a corresponding change in $M_{R}$ indicating thermal sensitivity. It can be seen that for $\Delta T=+25{ }^{\circ} \mathrm{C}$ the resilient modulus increases to $M_{R}=168 \mathrm{MPa}$, i.e., a relative change of $+44 \%$. This change was accompanied by an increase of the lateral-to-vertical effective stress ratio from $K_{0}=3.0$ to $K_{0}^{\Delta T}=5.7$. When $\Delta T=-25{ }^{\circ} \mathrm{C}$ the resilient modulus decreases to $M_{R}=84 \mathrm{MPa}$, i.e., a relative change of $-28 \%$. This change was accompanied by a drop of the lateral-to-vertical effective stress ratio from $K_{0}=3.0$ to $K_{0}^{\Delta T}=1.6$. Both the low and high $K_{0}^{\Delta T}$ 's are within an acceptable range indicating physically admissible results [39].

Referring next to Figs. 2(a-c), it can be noticed that the thermal sensitivity is influenced when 
varying the three resilient modulus parameters (the $k_{i}$ 's). While the general trend of increasing $M_{R}$ with increasing temperature level persists across all cases, the sensitivity increases with increasing each of the $k_{i}$ 's separately (and vice versa). The effect on thermal sensitivity when varying the Poisson's ratio is plotted in Fig. 2(d); it can be seen that the effect is marginal.

(a)

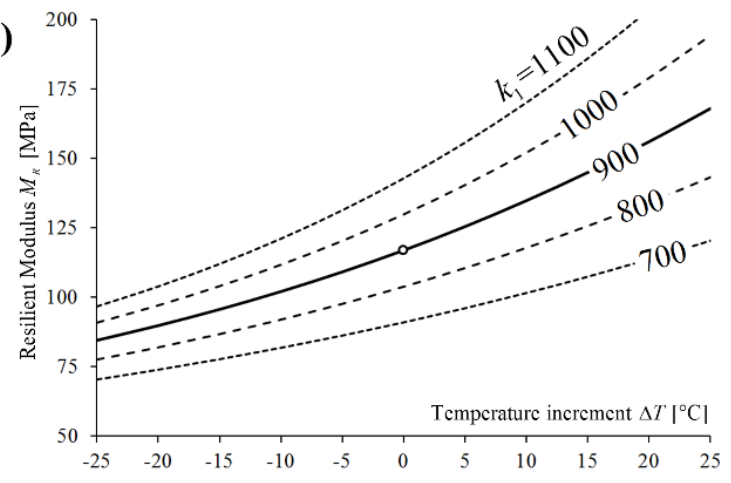

(c)

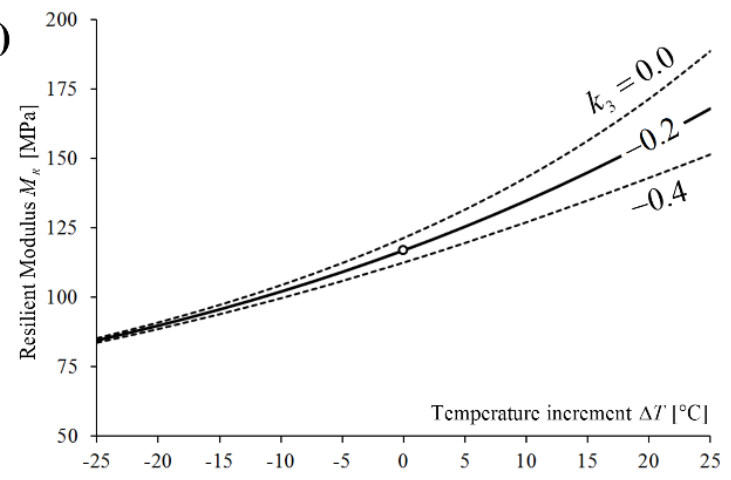

(b)

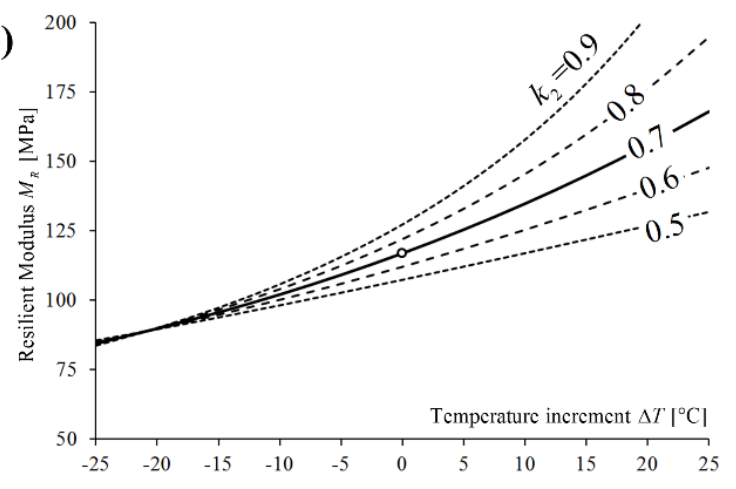

(d)

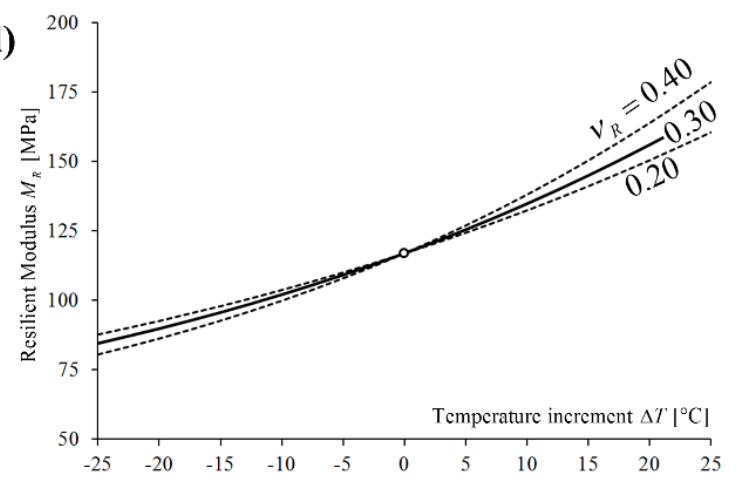

Fig. 2. Thermal sensitivity plots based on Eq. (5) of an UGL with Table 1 model parameters: (a) effect of varying resilient modulus parameter $k_{1}$, (b) effect of varying resilient modulus parameter $k_{2}$, (c) effect of varying resilient modulus parameter $k_{3}$, and (d) effect of varying resilient Poisson's ratio.

Fig. 3(a) deals with different $K_{0}$ values; it shows that the resulting effect on the $M_{R}-\Delta T$ curves is a vertical translation without shape change. This means that, in absolute terms, the thermal sensitivity is independent of the initial stress ratio. The effect of varying $z_{0}$ is plotted in Fig. 3(b); as can be seen, the effect also appears as a vertical translation of the reference $M_{R}$ curve without any change in shape, i.e., $M_{R}$ increases with increase in element depth. The effect of varying $S$ is plotted in Fig. 3(c); as can be seen, changes in moisture suction result in vertical translations of the reference $M_{R}$ curve without any change in shape, i.e., $M_{R}$ increases with increase in $|S|$. Therefore, in absolute terms, the initial stress conditions governed by $K_{0}, z_{0}$, and $S$ do not influence the thermal sensitivity of $M_{R}$. However, if the thermal sensitivity was assessed in relative terms - relative to the initial $M_{R}$ level - then larger $K_{0}, z_{0}$, or $|S|$ (or all three), would lessen the relative thermal sensitivity. Finally, with respect to Fig. 3(d), it can be seen that varying $\alpha$ impacts somewhat the thermal sensitivity. A larger thermal expansion coefficient yields higher sensitivity (and vice versa). In this connection, it should be noted that the chosen reference $\alpha$ value is representative of silica, while the plotted range applies to a wide variety of aggregate sources: basalt, marble, granite, sandstone, limestone, and dolomite [40-41]. 
(a)

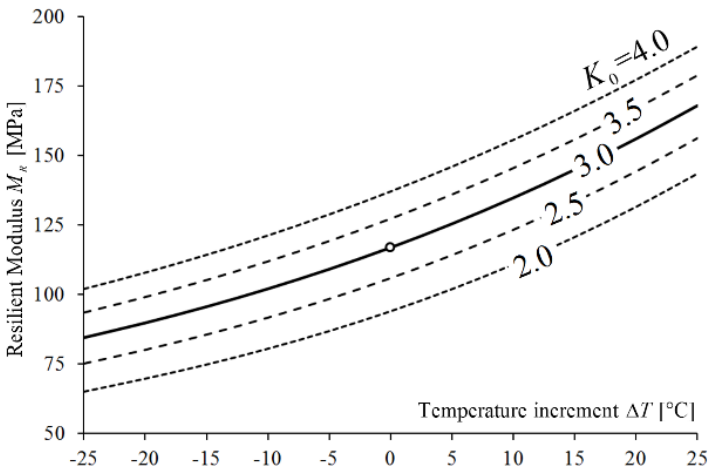

(c)

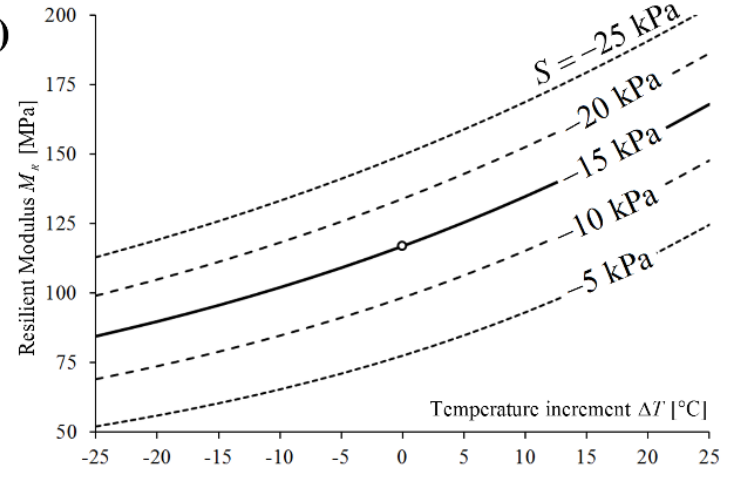

(b)

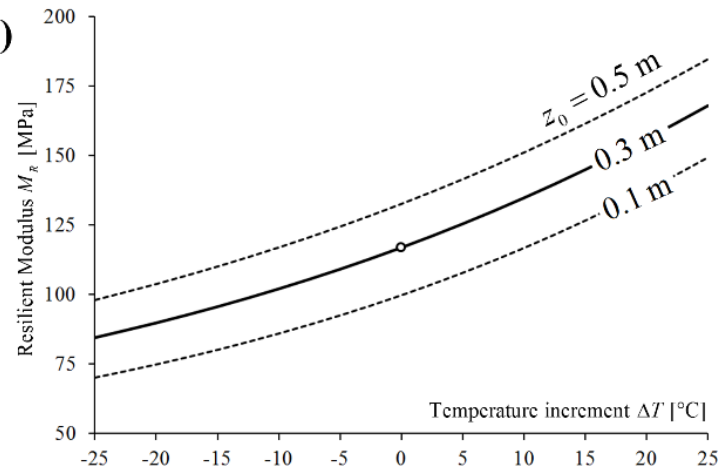

(d)

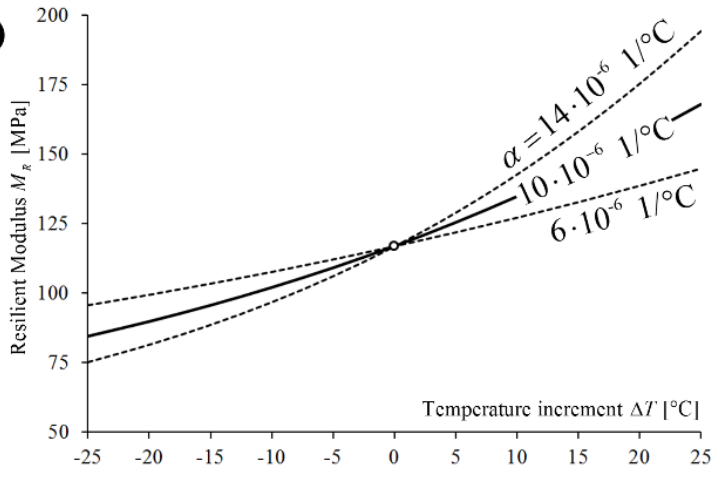

Fig. 3. Thermal sensitivity plots based on Eq. (5) of an UGL with Table 1 model parameters: (a) effect of varying the initial at-rest earth pressure coefficient, (b) effect of varying element depth, (c) effect of varying moisture suction, and (d) effect of varying the coefficient of linear thermal expansion.

\section{Discussion}

The model developed in this work was focused on isolating and subsequently quantifying the thermal sensitivity of UGLs resulting from temperature induced stress-state changes. The development was based on three main assumptions: (i) temperature profile changes are exogenous to the model, (ii) the mechanical behavior of UGLs is elastic, and (iii) the lateral dimensions of UGLs are infinite.

With respect to the first assumption, it should be noted that thermal conductivity, which is one of the factors determining temperature distribution with depth, is known to depend on density, initial stress conditions, and moisture content (or saturation ratio) [42-45]. Also, in actuality, there is some cross-interaction between moisture level and temperature [46-49]; particularly, an increase in temperature may be accompanied by a reduction in overall moisture content through evaporation or locally due to convective motion of the pore water - with a subsequent increase in pore water tension. On the other hand, if relative humidity increases and the moisture vapor cannot escape the pore space, then the surface tension of the pore water will reduce. All aforementioned effects are complex scenarios capable of impacting the resilient modulus. Currently these are not captured by the model, and must therefore be addressed separately if deemed important.

The second assumption, that of elastic behavior, is seminal to the applicability of Eq. (2), and therefore to the entire derivation and findings. It basically asserts that any pre-existing UGL stresses that control $M_{R}$ (treating moisture-change effects as marginal) are essentially timewise constant as long as the temperature level does not change. This assumption is deemed very realistic for densely packed particulate materials, as demonstrated in discrete element models [50,51], in laboratory compaction experiments on sand [52], in laboratory thermal cycling experiments on dense sand [34], in 
large-scale laboratory experiments on UGM compaction [53], in field investigations on compactioninduced stresses on retaining walls [54,55], and in application of geophysical exploration techniques to assess the in situ modulus of UGLs [56]. Finally, it is noted that there exists some experimental evidence that well-compacted UGMs under constant temperature exhibit time-dependent mechanical behavior, e.g., creep under constant level of load, and stress-relaxation under constant level of deformation [57]. Fortunately, these effects are only active over relatively short time intervals of the order of seconds and minutes. Across longer time scales of the order of hours, weeks, and months (for which temperature changes are relevant), the material behavior is essentially reversible and time-independent, supporting the applicability of Eq. (2).

The third assumption, of lateral infinity, is considered reasonable for most wide constructions such as multilane highways, airport pavements, seaport pavements, and parking lots. It may not apply to relatively narrow pavement systems such as railways, single-lane roads, bicycle paths, etc. To accommodate these situations the proposed approach can be slightly modified by considering the UGL as an infinitely long strip of finite width. Taking the $y$-axis to denote the strip width direction, Eq. (2) can be revisited with: $d \sigma_{1}=0$ (UGL free to expand or contract along the $z$-axis), $d \sigma_{3}=0$ (UGL free to expand or contract along the $y$-axis), and $d \varepsilon_{2}=0$ (UGL infinitely long in the $x$-axis direction). This set of conditions, in analogy to Eq. (3), yields: $M_{R} \alpha d T=d \sigma_{2}$ (note the absence of the Poisson's ratio). Subsequently, upon insertion of $M_{R}$ (Eq. (4)) with the corresponding stress expressions, i.e., $\sigma_{1}=z_{0} \gamma_{t}-S, \sigma_{2}=K_{0} \sigma_{1}+\Delta \sigma_{2}$, and $\sigma_{3}=K_{0} \sigma_{1}$, another transcendental equation can be formulated:

$$
\underbrace{\left(\frac{\left(k_{1} P_{a}\right)\left(\frac{\left(z_{0} \gamma_{t}-S\right)\left(1+2 K_{0}\right)+\Delta \sigma_{2}}{P_{a}}\right)^{k_{2}}}{\left(\frac{2 \sqrt{\left(z_{0} \gamma_{t}-S\right)^{2}\left(1-K_{0}\right)^{2}-\Delta \sigma_{2}\left(z_{0} \gamma_{t}-S\right)\left(1-K_{0}\right)+\left(\Delta \sigma_{2}\right)^{2}}}{3 \sqrt{2} P_{a}}+1\right)^{-k_{3}}}\right)}_{M_{R}} \alpha \Delta T=\Delta \sigma_{2}
$$

This equation applies to the case of a UGL that is constrained from thermally expanding (or contracting) only in one ( $x$-axis) direction. Therefore, compared to Eq. (5), it will predict reduced thermal sensitivity of about $50 \%$. Also in this case, the coefficient of at-rest earth pressure will only change in the $x$-axis direction.

\section{Conclusion}

This work investigated the thermal sensitivity (excluding frost action effects) of UGMs in pavement systems. The starting point for the analysis was that the resilient modulus of UGMs is governed by the prevailing effective stress-state, with material constants (e.g. the $k_{i}$ 's in Eq. (4)) that are essentially temperature independent. Subsequently, a model was developed to calculate stress-state changes in UGLs due to changes in temperature (Eq. (5)); it considered representative in situ boundary and initial conditions assuming no external loads are applied (see Fig. 1). The model was parametrically investigated, covering a wide range of characteristic input parameters (see Table 1).

The main conclusion from this investigation is that UGLs exhibit non-negligible thermal sensitivity above freezing conditions. This outcome was clearly demonstrated across all considered cases in the parametric investigation (see Figs. 2 and 3). Some validity of the findings can be derived from the fact that the extent of the calculated sensitivity matches reported field observations based on 
deflection testing [31,32]. Also, the model forecasts $M_{R}$ changes that coincide with seasonal factors traditionally applied to adjust field-measured moduli for subsequent design, for evaluating or reporting on structural condition, and for normalizing axle load conversion formulas [21,22,58-60]. This means that the work may be utilized to rationalize, at least in part, the selection and application of such seasonal factors.

Ultimately, the study shows that resilient modulus of UGLs is governed by an initial stress-state that is associated with a certain reference temperature level, and also a by the temperature change compared to the reference. Thus, another conclusion of practical importance that emerges from this work is that the timing of construction operations is important. UGLs compacted at the low-end of the expected temperature range will only experience increase in their resilient moduli under service, thus benefitting from the thermal sensitivity. On the other hand, UGLs compacted at the high-end of the expected temperature range will exhibit decreased resilient moduli under service.

\section{References}

[1] Seed, H. B., Chan, C. K., and Lee, C. E. Resilience Characteristics of Subgrade Soils and Their Relation to Fatigue Failures in Asphalt Pavements. Proceeding of the International Conference on the Structural Design of Asphalt Pavements, Vol. 1, Ann Arbor, USA, 1962. pp. 611-636.

[2] Mitry, F. G. Determination of the Modulus of Resilient Deformation of Untreated Base Course Materials. PhD thesis, University of California, Berkeley, Berkeley, California, 1964.

[3] Seed, H. B., Mitry, F. G., Monismith, C. L., and Chan, C. K. Prediction of Flexible Pavement Deflections from Laboratory Repeated-Load Tests, NCHRP Report 35, Transportation Research Board, 1967.

[4] Hicks, R. G., and Monismith, C. L. Factors Influencing the Resilient Response of Granular Materials, Highway Research Record, 1971. 345: 15-31.

[5] Allen, J. J. The Effects of Stress History on the Resilient Response of Soils. Report AD-762 194, Army Construction Engineering Research Laboratory, 1973.

[6] Boyce, J. R. The Behaviour of a Granular Material under Repeated Loading. PhD thesis, University of Nottingham, 1976.

[7] Sweere, G. T. H. Unbound Granular Bases for Roads. PhD Thesis, Delft University of Technology, The Netherlands, 1990.

[8] Adu-Osei, A. Characterization of Unbound Granular Layers in Flexible Pavements. Report ICAR/502-3, Texas Transportation Institute, Texas A\&M University System College Station, Texas, 2000.

[9] Stolle, D., Guo, P., and Liu, Y. Resilient Modulus Properties of Granular Highway Materials, Canadian Journal of Civil Engineering, 2009. 36(4): 639-654.

[10] Cary, C. E., and Zapata, C. Resilient Modulus for Unsaturated Unbound Materials. Road Materials and Pavement Design, 2011. 12(3): 615-638.

[11] Yau, A., and Von Quintus, H. L. Study of LTPP Laboratory Resilient Modulus Test Data and Response Characteristics. Final Report, FHWA-RD-02-051, USDOT, FHWA, 2002.

[12] Han, Z., and Vanapalli, S. K. Prediction of the Resilient Modulus of Unsaturated Base-Course materials. Proceedings of the International Foundations Congress and Equipment Expo, San Antonio, Texas, 2015. pp. 2112-2121.

[13] Lytton, R. L., Uzan, J., Fernando, E. G., Roque, R., Hiltunen, D., and Stoffels, S. M. Development and Validation of Performance Prediction Models and Specifications for Asphalt Binders and Paving Mixes, SHRP-A-357, Washington, DC, 1993. 
[14] Lekarp, F., Isacsson, U., and Dawson, A. R. State of the Art. I: Resilient Response of Unbound Aggregates. Journal of Transportation Engineering, 2000, 126(1): 66-75.

[15] Liu, Y., Stolle, D., Guo, P., and Emery, J. Stress-Path Dependency of Resilient Behaviour of Granular Materials. International Journal of Pavement Engineering, 2014. 15(7): 614-622.

[16] Lade, P. V., and Nelson, R. B. Modelling the Elastic Behaviour of Granular Materials. International Journal of Numerical and Analytical Methods in Geomechanics, 1987. 11: 521542.

[17] Park, S. W. Analysis of Stress-Dependent Behavior in Conventional Asphalt Pavements. KSCE Journal of Civil Engineering, 2001 5: 387-395.

[18] Liu, Y. Stress-Path Dependency of Resilient Behaviour of Granular Materials. PhD Thesis, McMaster University, 2010.

[19] Soleimanbeigi, A., Shedivy, R. F., Tinjum, J. M., and Edil, T. B. Climatic Effect on Resilient Modulus of Recycled Unbound Aggregates. Road Materials and Pavement Design, 2015. 16: 836-853.

[20] Jin, M. S., Lee, K. W., and Kovacs, W. D. Seasonal Variation of Resilient Modulus of Subgrade Soils. Journal of Transportation Engineering 1994. 120: 603-616.

[21] Ovik, J., Birgisson, B., and Newcomb, D. E. Characterizing Seasonal Variations in Flexible Pavement Material Properties. Transportation Research Record 1684, 1999. pp. 1-7.

[22] Richter, C. A. Seasonal Variations in the Moduli of Unbound Pavement Layers. Report FHWAHRT-04-079, Federal Highway Administration, McLean, VA, 2006.

[23] Zapata, C. E., Andrei, D., Witczak, M. W., and Houston, W. N. Incorporation of Environmental Effects in Pavement Design. Road Materials and Pavement Design, 2007. 8: 667-693.

[24] Rahman, M. S., Characterising the Deformation Behaviour of Unbound Granular Materials in Pavement Structures. PhD Thesis, KTH Royal Institute of Technology, Stockholm, Sweden, 2015.

[25] Smoltczyk, U., Hilmer, K., Franke, E., and Schuppener, B. Earth Pressure Variations due to Temperature Change. Proceedings of the $9^{\text {th }}$ International Conference on Soil Mechanics and Foundation Engineering, 1976. Vol. I: 725-733.

[26] Zhang, Q., Britton, M. G., Leitgeb, J. M. Thermally Induced Pressures in an On-Farm Grain Storage Bin. Canadian Agricultural Engineering, 1993. 35(1): 51-56.

[27] Bentler, J. G., Labuz, J. F., and Schultz, A. E. Earth Pressure Behind a Retaining Wall, Report No. 2005-142005, Minnesota Department of Transportation, St. Paul, Minnesota, 2005.

[28] Iskander, M. Relationship Between Temperature and Earth Pressure for a Rigidly Framed Earth Retaining Structure. Geotechnical and Geological Engineering, 2013. 31(2): 519-539.

[29] Vargas, W. L., and McCarthy, J. J. Thermal Expansion Effects and Heat Conduction in Granular Materials. Physical Review E, 2007. 76: 041301(1-8).

[30] Zhao, S., Evans, T. M., Zhou, X., and Zhou, S. Discrete Element Method Investigation on Thermally-Induced Shakedown of Granular Materials. Granular Matter, 2017. 19: 1-11.

[31] Chandra, D., Lytton R. L., and Yang, W. Effects of Temperature and Moisture on Low-Volume Roads. Research Report, FHWA/TX89/473-2, Texas Transportation Institute, The Texas A\&M University System College Station, Texas, 1988.

[32] Chandra, D., Chua, K. M., and Lytton R. L. Effects of Temperature and Moisture on the Load Response of Granular Base Course Material in Thin Pavements. Transportation Research Record, 1989. 1252: 33-41.

[33] O'Sullivan, C. Particulate Discrete Element Modelling: A Geomechanics Perspective. Chapman and Hall/CRC, Boca Raton, Florida, 2014. 
[34] Ng, C. W. W., Wang, S. H., and Zhou, C. Volume Change Behaviour of Saturated Sand under Thermal Cycles. Géotechnique Letters, 2016. 6: 124-131.

[35] Nadimi, S., and Fonseca, J. Enhancing Soil Sample Preparation by Thermal Cycling. Géotechnique, 2016. 66: 953-958.

[36] Liu, H., Liu, H., Xiao, Y., and McCartney, J. S. Influence of Temperature on the Volume Change Behavior of Saturated Sand. Geotechnical Testing Journal, 2018. 41: 747-758.

[37] Westergaard, H. M. Analysis of Stresses in Concrete Pavements due to Variations of Temperature. Proceedings $6^{\text {th }}$ Annual Meeting of the Highway Research Board, Washington, D.C., 1927, pp. 201-215.

[38] Antia, H. M. Numerical Methods for Scientists and Engineers. Hindustan Book Agency, New Delhi, India, 2012.

[39] Levenberg, E., and Garg, N. Estimating the Coefficient of At-Rest Earth Pressure in Granular Pavement Layers. Transportation Geotechnics, 2014. 1: 21-30.

[40] Johnson, W. H., and Parsons, W. H. Thermal Expansion of Concrete Aggregate Materials. Journal of Research of the National Bureau of Standards, 1944. 32: 101-126.

[41] Skinner, B. J. Thermal Expansion, in Handbook of Physical Constants (S. P/ Clark, Jr., ed.), Geological Society of America Memoir 97, Section 6, pp. 75-96.

[42] Chen, S. Thermal Conductivity of Sands. Heat Mass Transfer, 2008. 44: 1241-1246

[43] Hamdhan, I. N., and Clarke, B. G. Determination of Thermal Conductivity of Coarse and Fine Sand Soils. Proceedings World Geothermal Congress, Bali, Indonesia, 2010.

[44] Haigh, S. K. Thermal conductivity of sands. Géotechnique, 2012. 62: 617-625.

[45] Alrtimi, A., Rouainia, M., Haigh, S. Thermal Conductivity of a Sandy Soil. Applied Thermal Engineering, 2016. 106: 551-560.

[46] Gurr, C. G., Marshall, T. J., and Hutton J. T. Movement of Water in Soil due to a Temperature Gradient. Soil Science, 1952. 74: 335-345.

[47] Cheung, S. C. H., Gray, M. N., Yong, R. N., and Mohamed, A. M. O. The Effects of Moisture Content, Salinity and Temperature on the Load-Bearing Capacity of a Dense Clay-Based Backfill. Material Research Society Symposium Proceedings, 1990. 212: 491-498.

[48] Philip, J. R., and DeVries, D. A. Moisture Movement in Porous Materials under Temperature Gradients. Transactions American Geophysical Union, 1957. 38: 222-232.

[49] Bidarmaghz, A., and Narsilio, G. A. Shallow Geothermal Energy: Emerging Convective Phenomena in Permeable Saturated Soils. Géotechnique Letters, 2016. 6: 1-5.

[50] Pei, T., and Yang, X. Compaction-Induced Stress in Geosynthetic-Reinforced Granular Base Course - A Discrete Element Model. Journal of Rock Mechanics and Geotechnical Engineering, 2018. 10: 669-677.

[51] Balevičius, R., and Markauskas, D. Numerical Stress Analysis of Granular Material. Mechanics, 2007. 66(4): 12-17.

[52] Mesri, G., and Vardhanabhuti, B. Coefficient of Earth Pressure At Rest for Sands subjected to Vibration. Canadian Geotechnical Journal, 2007. 44: 1242-1263.

[53] Zeilmaker, J., and Henny, R. J. The Measurement of Residual Stresses due to Compaction in Granular Materials. Proceedings of the International Symposium on Unbound Aggregates in Roads (UNBAR3), University of Nottingham, UK, R.H. Jones and A.R. Dawson (Eds.), 1989. 19: 159-168.

[54] Ingold, T. S. The Effects of Compaction on Retaining Walls. Géotechnique, 1979. 29(3): 265283.

[55] Massarsch, K. R., and Fellenius, B. H. Vibratory Compaction of Coarse-Grained Soils. 
Canadian Geotechnical Journal, 2002. 39(3): 695-709.

[56] Papadopoulos, E., Cortes, D. D., and Santamarina, J. C. In-Situ Assessment of the StressDependent Stiffness of Unbound Aggregate Bases: Application in Inverted Base Pavements. International Journal of Pavement Engineering, 2016. 17(10): 870-877.

[57] Levenberg, E. Viscoelastic-Viscoplastic Characterization of Unbound Granular Material. Advances in Civil Engineering Materials, 2014. 3(1): 21-42.

[58] Uhlmeyer, J. S., Mahoney, J. P., Hanek, G., Wang, G., Copstead, R. L., and Janssen, D. J., Estimation of Seasonal Effects for Pavement Design and Performance - Volume 1. Research Report, FHWA-FLP-95-006, Federal Highway Administration, Washington, DC, 1996.

[59] Ovik, J. M., Birgisson, B., and Newcomb, D. E. Characterizing Seasonal Variations in Pavement Material Properties for use in a Mechanistic-Empirical Design Procedure. Research Report MN/RC-2000-35, Minnesota Department of Transportation, Minneapolis, MN, 2000.

[60] Zhang, H., Gong, M, and Yu, T. Modification and application of axle load conversion formula to determine traffic volume in pavement design. International Journal of Pavement Research and Technology, 2018. 11: 582-593. 